\title{
A Method for Removing a Stripe from the Coating of a Fabry-Perot Mirror
}

\author{
S. J. Perry
}

L. L. Steinmetz

October 1997

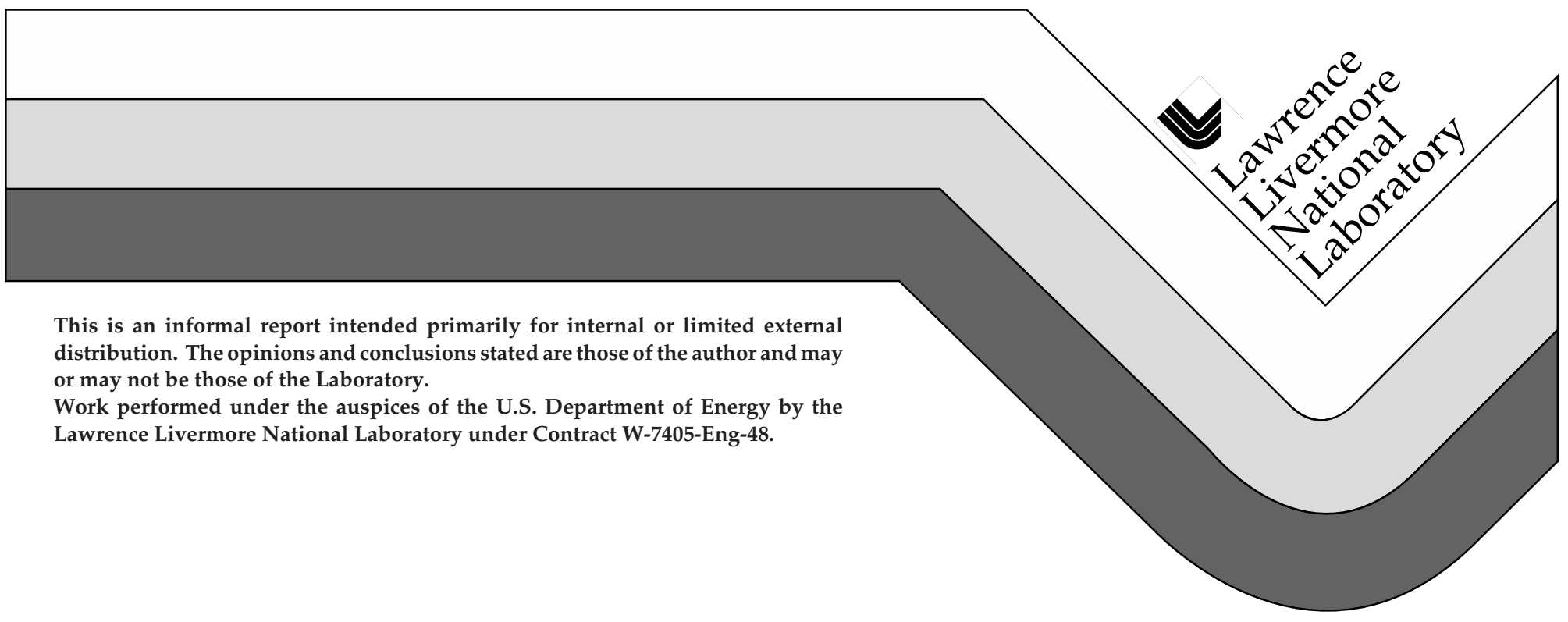




\section{DISCLAIMER}

This document was prepared as an account of work sponsored by an agency of the United States Government. Neither the United States Government nor the University of California nor any of their employees, makes any warranty, express or implied, or assumes any legal liability or responsibility for the accuracy, completeness, or usefulness of any information, apparatus, product, or process disclosed, or represents that its use would not infringe privately owned rights. Reference herein to any specific commercial product, process, or service by trade name, trademark, manufacturer, or otherwise, does not necessarily constitute or imply its endorsement, recommendation, or favoring by the United States Government or the University of California. The views and opinions of authors expressed herein do not necessarily state or reflect those of the United States Government or the University of California, and shall not be used for advertising or product endorsement purposes.

This report has been reproduced directly from the best available copy.

Available to DOE and DOE contractors from the Office of Scientific and Technical Information P.O. Box 62, Oak Ridge, TN 37831

Prices available from (615) 576-8401, FTS 626-8401

Available to the public from the National Technical Information Service

U.S. Department of Commerce 5285 Port Royal Rd. Springfield, VA 22161 


\title{
A METHOD FOR REMOVING A STRIPE FROM THE COATING OF A FABRY-PEROT MIRROR
}

\author{
Stephen J. Perry \\ Lloyd L. Steinmetz
}

$\underline{\text { ABSTRACT }}$

We describe a method for removing a stripe from the coating of a Fabry-Perot mirror. This is accomplished by scraping off the soft coating with a finely lapped steel blade mounted on a precision mechanism to accurately position the blade and guide it for straight cuts. The width of the stripe is determined by selecting a blade of desired size. Previous methods and attempts are discussed.*

\section{INTRODUCTION}

We are successfully using a Fabry-Perot interferometer with a stripe removed from the coating of the input mirror to greatly increase the light throughput of the system. McMillan and Steinmetz ${ }^{(1)}$ have analyzed the affect of the striped mirror on the efficiency of the system; this report discusses the current method of producing stripes of specified size and quality as well as previous attempts.

\section{SYSTEM REQUIREMENTS}

To fully utilize the benefits of this method the stripe removed from the coating of the mirror must meet several conditions: it must be of a specified width depending on mirror separation (usually $500 \mu \mathrm{m}$ to $800 \mu \mathrm{m}$ ); the edges of the stripe must be straight and parallel; the boundary between the intact coating and the clean glass in the stripe must be as narrow as practical (less than about $40 \mu \mathrm{m}$ ); the coating must be removed as cleanly as possible; the underlying mirror substrate must remain intact and undamaged; the mirror must preserve its $\lambda / 100$ flatness; and the stripe produced must be properly oriented to both the optical axis and the mirror wedge.

\section{PREVIOUS ATTEMPTS}

Coatings can be applied to a Fabry-Perot mirror by means of two methods: a hard coating which is applied hot and a soft coating deposited at ambient temperature. The hard coating is quite durable and can be cleaned, however we have noticed that mirrors coated in this manner have a curvature of approximately $\lambda / 16$. Inasmuch as we do not see this curvature in mirrors with cold coatings we surmise that the process leaves stresses in the mirror. This amount of degradation is unacceptable for velocity applications therefore we only use mirrors with cold coatings.

We have investigated three methods of producing a stripe on a Fabry-Perot mirror: a) chemical photo etching, b) ion milling, and c) mechanical scraping. Chemical photo etching requires a photoresist to be applied directly to the mirror coating. This process is unsuitable for use with soft coatings because they are extremely fragile and would be damaged by any contact to their surface. They are therefore limited to treatment by either ion milling or mechanical scraping. Discussions with Chow et. al. ${ }^{(2)}$ led to the construction of a mask to facilitate ion etching of the coating in a vacuum chamber. Several trial runs were made on a practice mirror varying beam profile, energy, distance, and angle of incidence. We found that we were unable to adequately control the etch rate to give us 
complete removal of the coating without also etching into the substrate as well as producing unacceptable roll off of the edges (fig. 1).

Bissenger ${ }^{(3)}$ has demonstrated that the soft coating on a Fabry-Perot mirror could be removed by carefully scraping with a sharp hand held instrument. We decided that a blade of the proper geometry mounted in a precision holder could be used to cut an accurate stripe of defined width, location, and straightness.

\section{DESCRIPTION OF THE STRIPE CUTTER}

The stripe cutter consists of a finely lapped steel blade mounted on a pivot arm which in turn is part of a carriage that translates over the mirror surface. The carriage is fitted with four linear ball bearings and translates on two precision shafts. The shafts are mounted on a base that serves as the lapping base and can be assembled to the mirror holder (fig. 2).

The blade is made from a commercial razor knife blade which is manufactured from a fine grain hardened steel designed to take a keen edge. The blade is first wire electric discharge machined to the specified profile and cutting width then lapped to a fine edge (fig. 3). The lapping is done on a glass plate using successively finer grades of diamond paste progressing from 3.0 micron to 1.0 micron and finishing with 0.5 micron. The blade is clamped in its holder in the pivot arm during the entire lapping process and one side is completed before the blade is reversed and the procedure repeated for the other side. The fixture is set so that the lapping process produces a blade with a 70 degree included angle (fig. 4).

The entire striping mechanism is then assembled to a holding fixture into which the mirror has been mounted. This fixture places the mirror a predetermined distance below the striping mechanism so that the blade contacts the mirror with a 10 degree back clearance. Adjustable stops are fitted to the carriage base to limit overtravel of the carriage and a detent is provided to lock the blade in the raised position and prevent it from inadvertently dropping and damaging the mirror.

\section{THE STRIPING PROCESS}

The technique of striping a Fabry-Perot mirror begins with a determination of the stripe width desired. A blade of that width is then selected, mounted in the pivot arm and lapped on both sides with the diamond paste. Early effort were performed with modified razor blades using the factory stropping. the very shallow included angle of the blade was too weak to withstand the moderate downward pressure during striping. This pressure caused burnishing of the blade and resultant scoring of the substrate (fig. 5). Our diamond lapped blades with a 70 degree included angle are more robust than razor blades and give better results.

To be effective the stripe must be oriented and positioned accurately. The cutting mechanism and mirror holder are precision machined so that the stripe will be cut down the center of the mirror. The mirror is then rotated in its holder in order to properly orient the stripe. With the cutting mechanism mounted on the mirror holder the blade is lowered and a trial cut is made on the outside edge of the mirror. The cutting operation is viewed with a stereo microscope equipped with both top and bottom illumination. The trial cut is inspected and if necessary the cutting mechanism can be shimmed on one side to effect uniform material removal (fig. 6). The soft coatings are made of a dielectric material such as zinc sulfide/magnesium fluoride in as many as 24 layers. When the coatings are scraped pieces of material will both build up around the cutting blade like snow chip off like ice 
(fig. 7). This loose material electrostatically binds to the surface of the mirror and is difficult to remove. It causes scatter and loss of light and induces cross talk. To minimize this problem we fit a small vacuum tube close to the blade to draw away the loosened material.

After a cut of several millimeters is made the blade is lifted to inspect the stripe. If the stripe looks clean and satisfactory the blade is wiped clean and lowered into the stripe to continue cutting. Residual adherent coating material left in the stripe, squeaking and chatter are signs the blade needs relapping. The cutting mechanism registers on the mirror holder so the blade returns to very nearly the same position after lapping. Work progresses until the entire mirror is striped (fig. 8).

\section{CURRENT EFFORTS}

We have constructed several different mirror holders to enable us to successfully stripe 40mm and 70mm Burleigh mirrors, 70mm Tec Optic mirrors and rectangular solid etalons. The same cutting mechanism was used each time by selecting a blade of appropriate width.

\section{References:}

1. McMillan, L. L. Steinmetz, "Striped Fabry-Perots: Improved Efficiency for Velocimetry”, UCRL-102596 submitted to SPIE Conference San Diego, CA, 1990.

2. R. Chow, M. Benapfl, B. Frazier, G. Loomis, "Beam Characterization of an Ion Source for Etching”, internal LLNL memo, 1990.

3. Private communication, Horst Bissenger, LLNL 1990.

*U.S. patent No. 5,307,718 “Apparatus and Process for Removing a Predetermined Portion of Reflective Material from Mirror". 
Page 4

\section{$\Longrightarrow$}
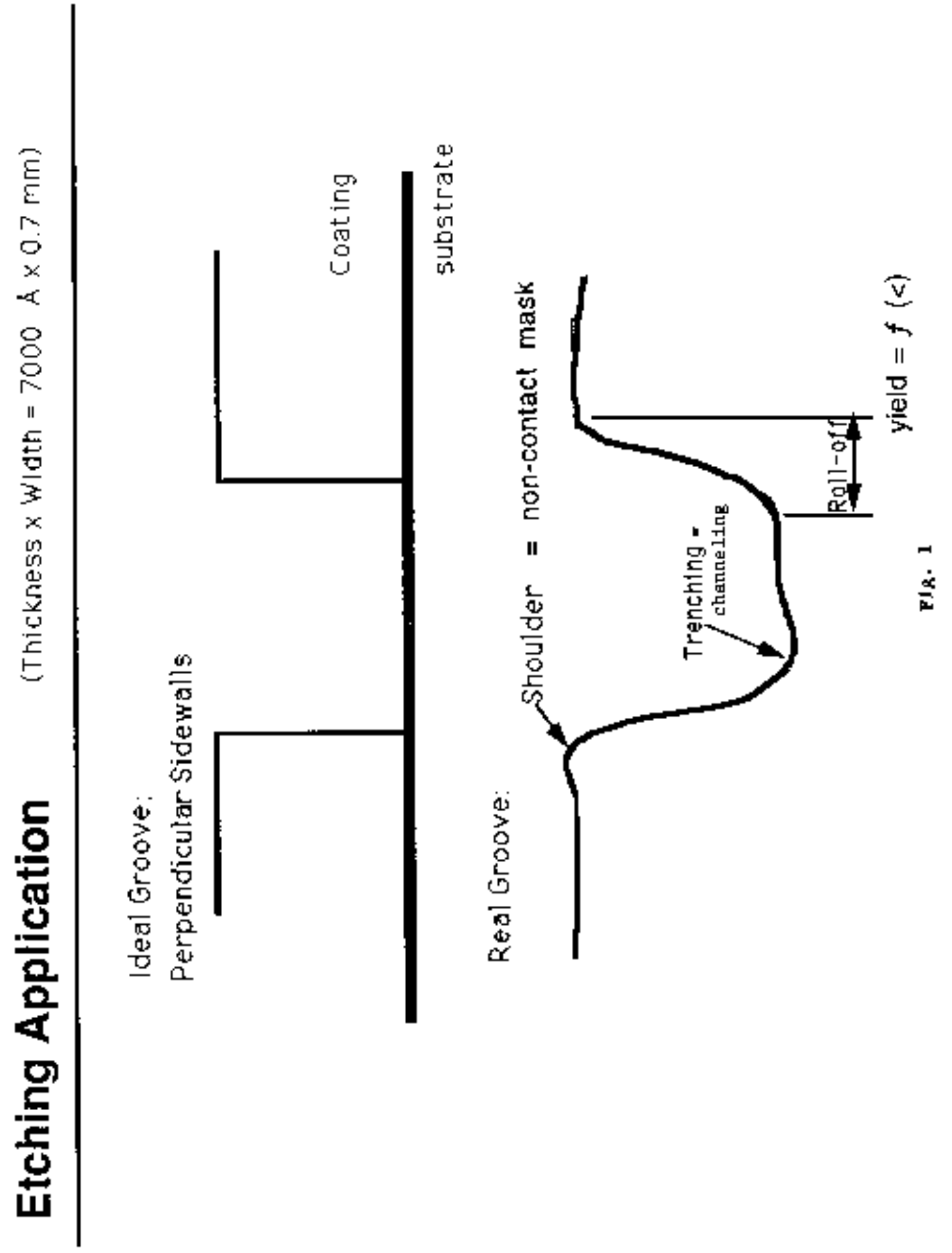
Page 5

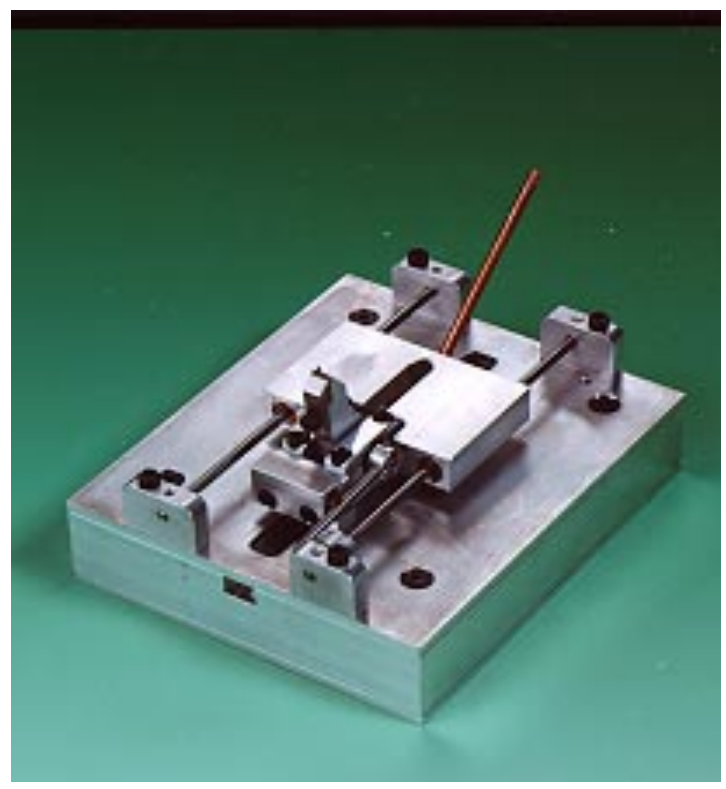

Fig. 2

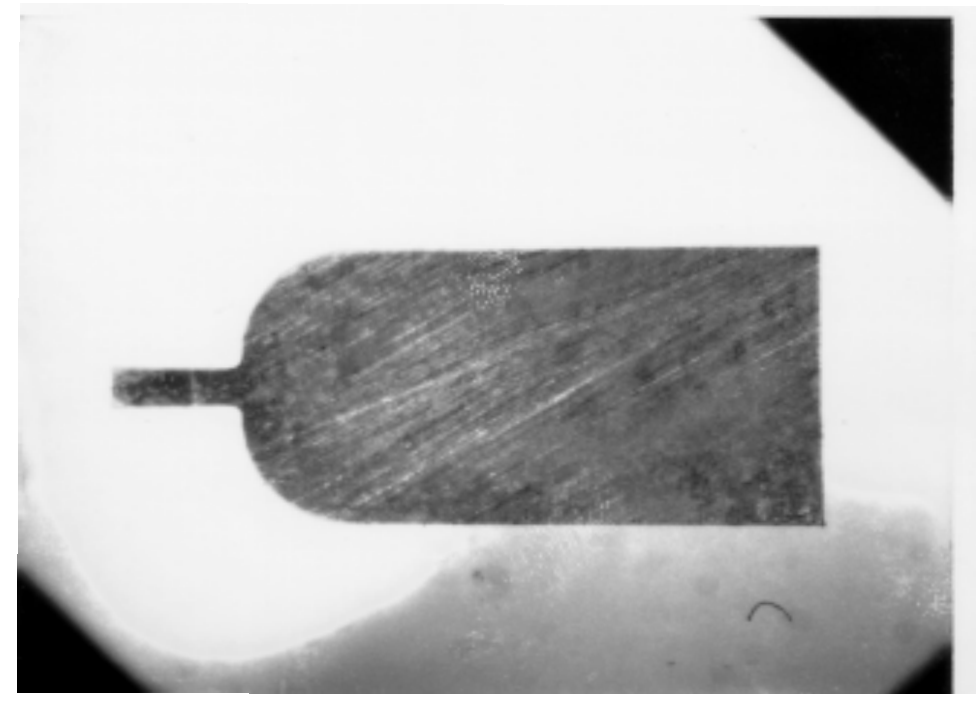

Fig. 3

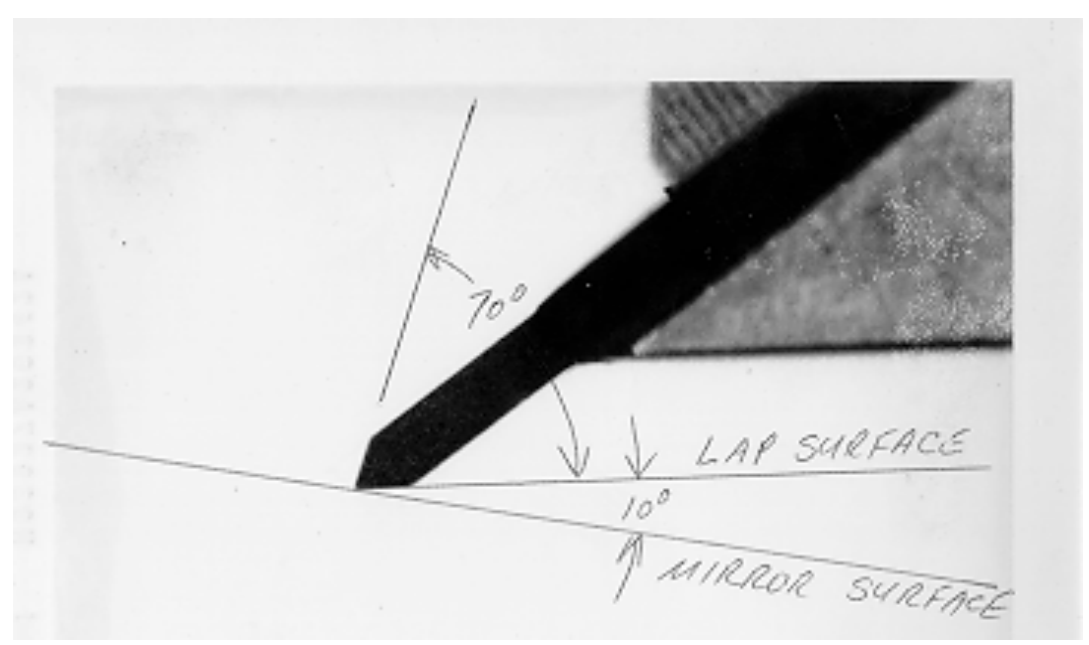

Fig. 4 
Page 6

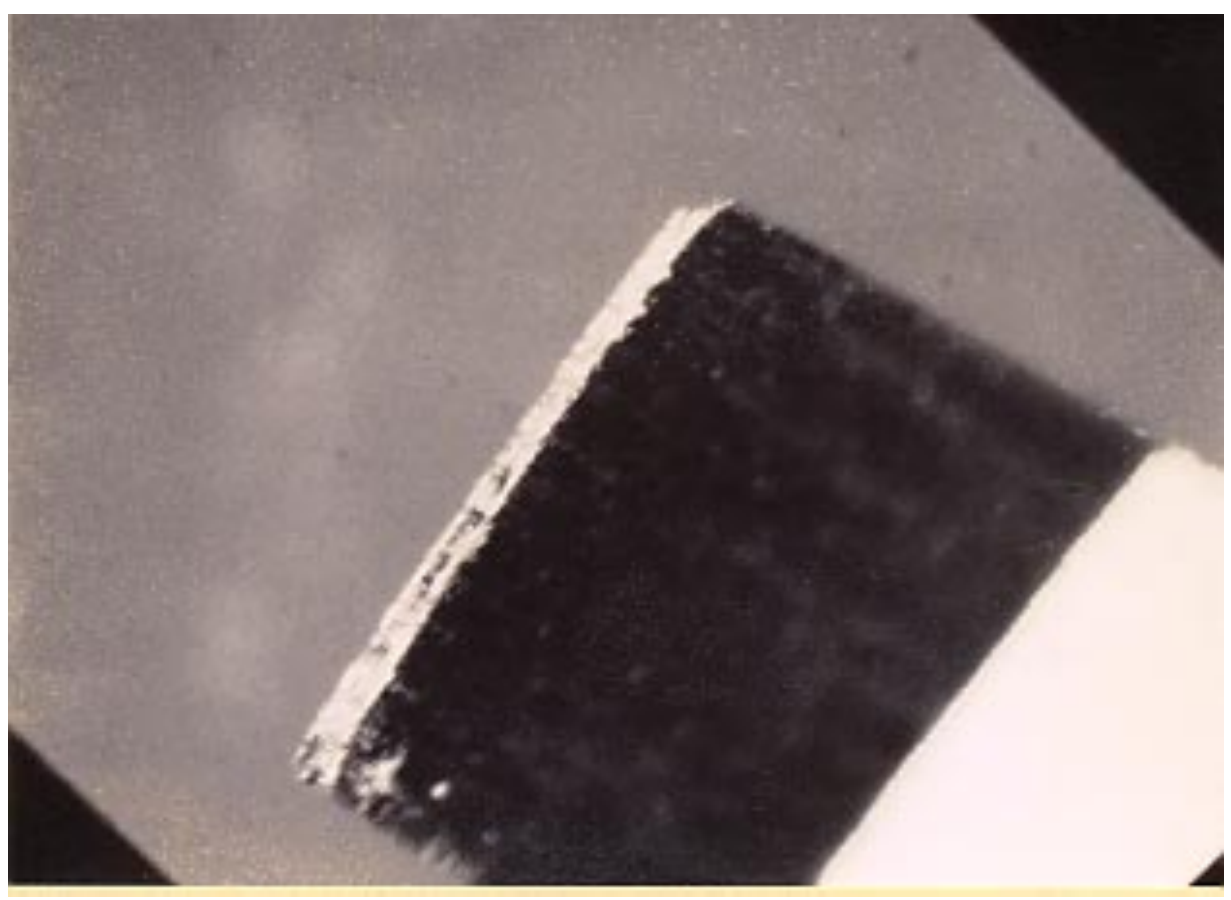

Fig. 5

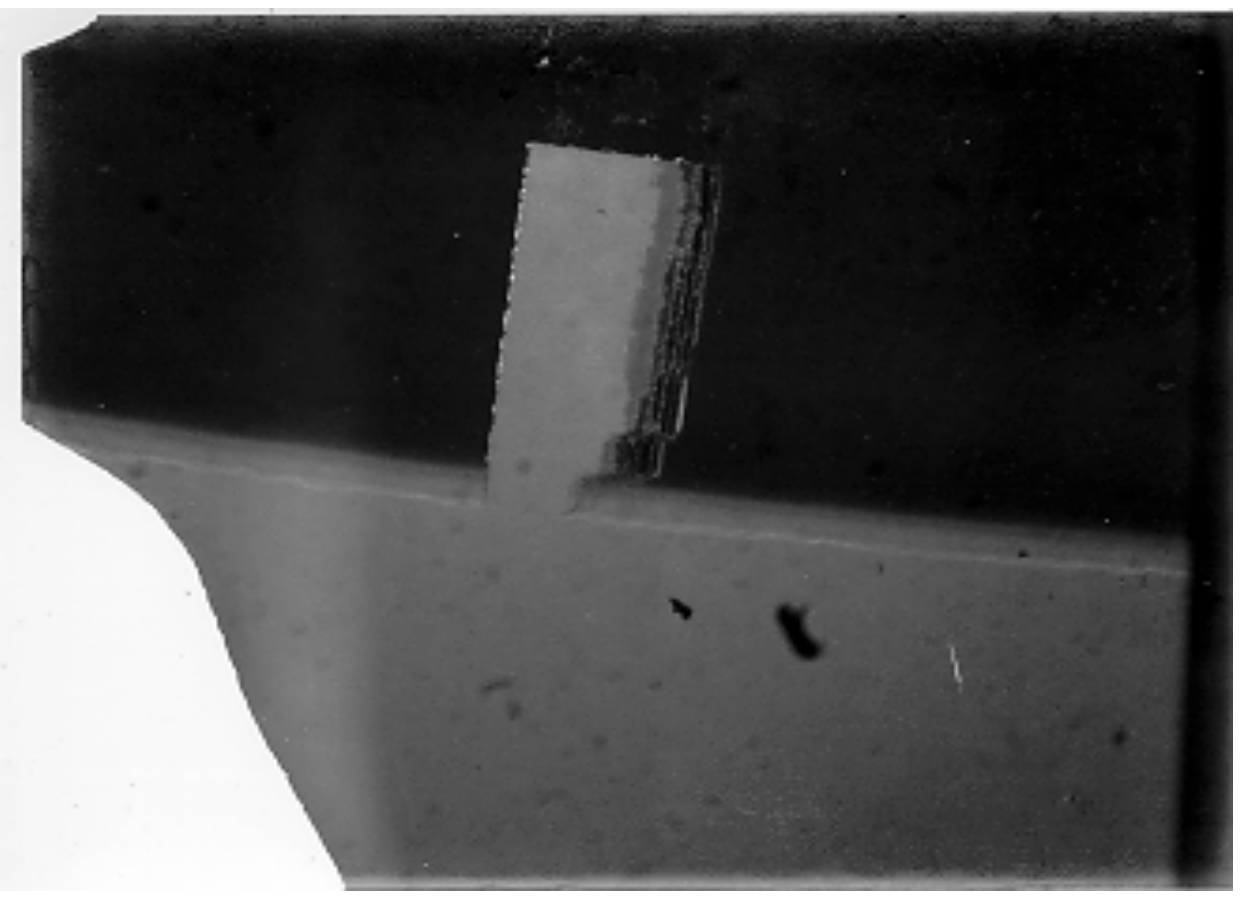

Fig. 6 


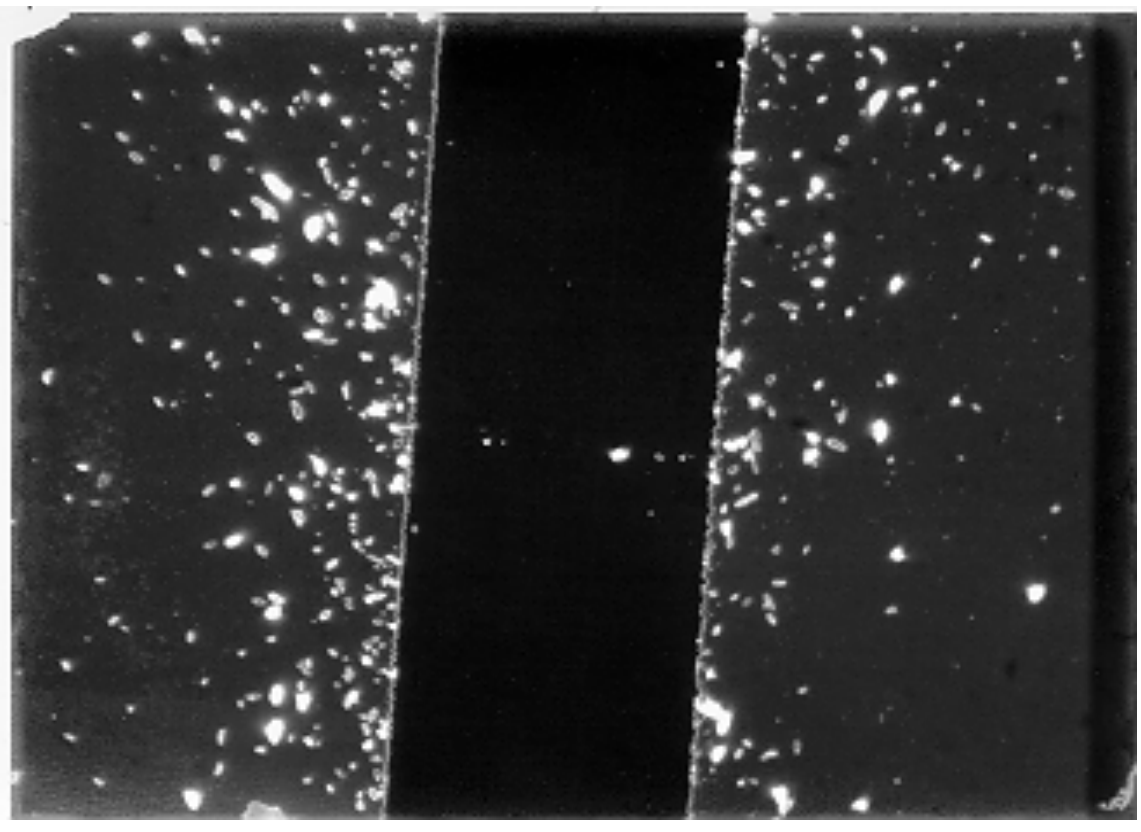

Fig. 7

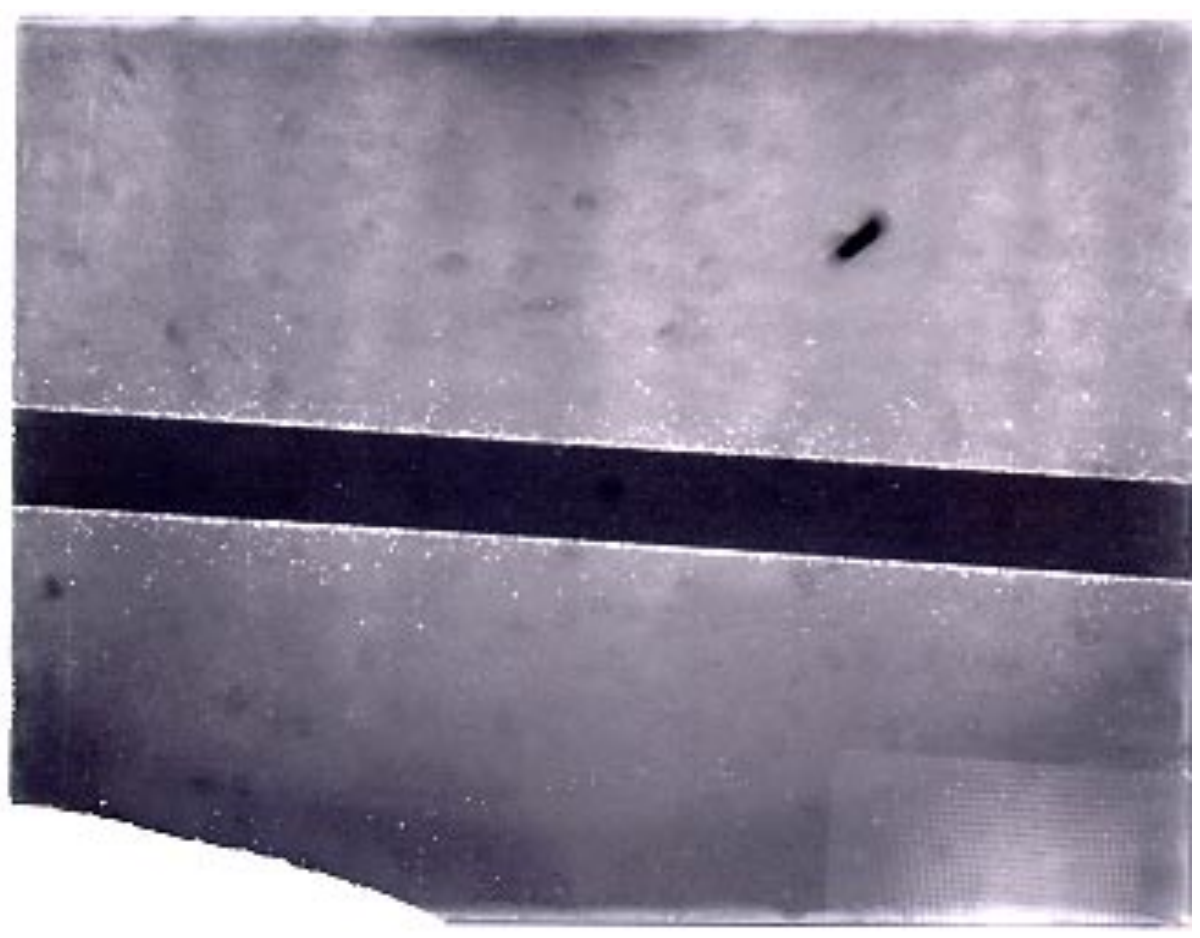

Fig. 8 


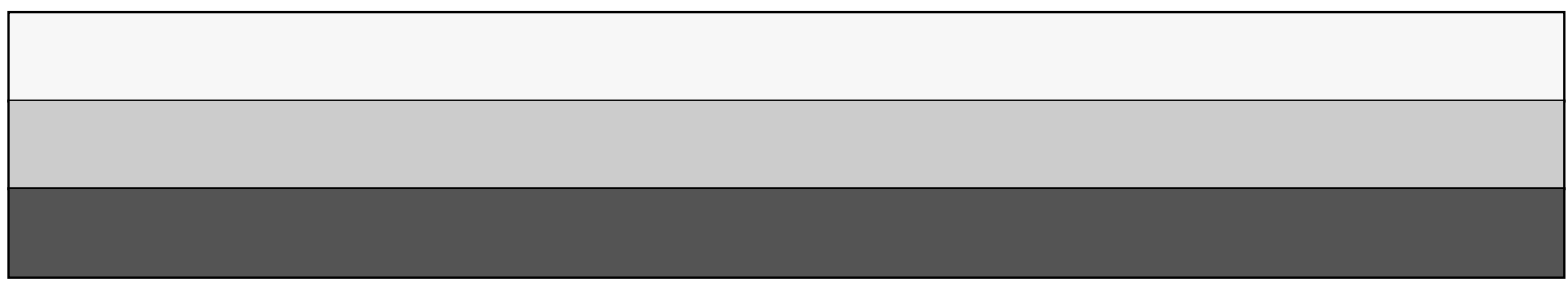

